\title{
When the forest calls: My experience on the Primate Behavioural Ecology Field School in Cambodia ${ }^{1}$
}

\section{Cynthia Parayiwa}

\begin{abstract}
Biological anthropology is deeply rooted in developing a better understanding of the behaviour and biology of humans and nonhuman primates. Though the classroom remains an effective tool for sharing theories and discussing concepts, behavioural studies continue to be enriched by the opportunity to enter the field and make real world observations. This essay shares how the Primate Behavioural Ecology Field School in Cambodia provided the opportunity for undergraduate and postgraduate students to observe and report on nonhuman primates within their natural forest habitat. Based at the Veun Sai-Siem Pang Conservation Area in northeast Cambodia, the field school allowed students to not only collect and report on behavioural and ecological data, but simultaneously experience local environmental conservation efforts in practice.
\end{abstract}

\section{Keywords}

field, methodology, Cambodia, nonhuman primate

1 An undergraduate course offered by the School of Archaeology and Anthropology (BIAN3018/6018): programsandcourses.anu.edu.au/course/BIAN3018. 


\section{Introduction}

Over three weeks in early January 2014, I had the opportunity to travel to northeast Cambodia and study local nonhuman primate species. Getting involved in field research at the end of my three-year science degree was an experience that exceeded my expectations; not only by giving me invaluable research experience beyond lectures and laboratories, but also broadening my interests and future study prospects. Through this field school, I was able to garner expertise in the collection and analysis of qualitative and quantitative behavioural, ecological and biological data. Being able to grasp and apply these skills in a practical setting and in an unpredictable environment was something I am grateful for when reflecting back on my undergraduate studies.

\section{Field site}

The course itself ran over three weeks at Veun Sai-Siem Pang Conservation Area (VSSPCA) in Virachey National Park, Cambodia (Figures 1 and 2). VSSPCA is one of the few protected areas that lie within the Indo-Burma biodiversity hotspot, which is home to about 130 mammalian species (King et al. 2016). The site also plays host to several vulnerable and endangered species, which include a variety of nonhuman primates I had the opportunity to observe in varying capacities. Before entering the field, we received training to cover necessary research methodologies in order to 'hit the ground running'. During my time on site, I was fortunate enough to observe the brightly marked and rare redshanked doucs (Pygathrix nemaeus), the newly described northern buff-cheeked crested gibbons (Nomascus annamensis) and the endangered silvered langurs (Trachypithecus margarita). Fieldwork involved the collection of behavioural data from a habituated group of gibbons, doing ad libitum observations on unhabituated langur groups and conducting ecological transacts to collect data on local vegetation. 


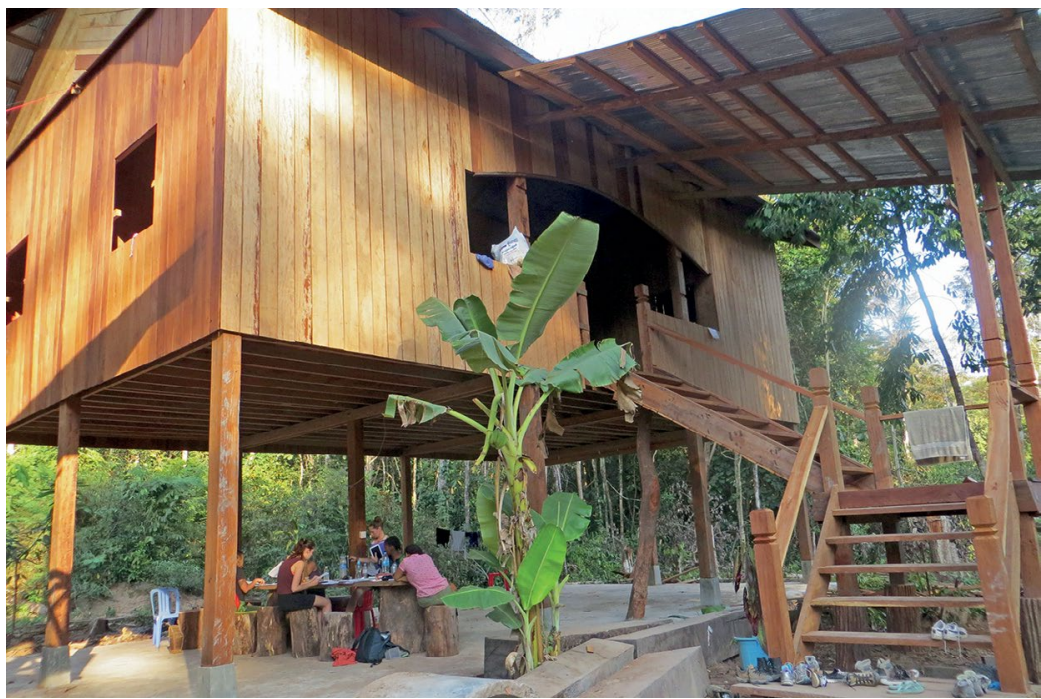

Figure 1: Raised student share house at Veun Sai-Siem Pang Conservation Area base camp with open-air study area below Source: Author.

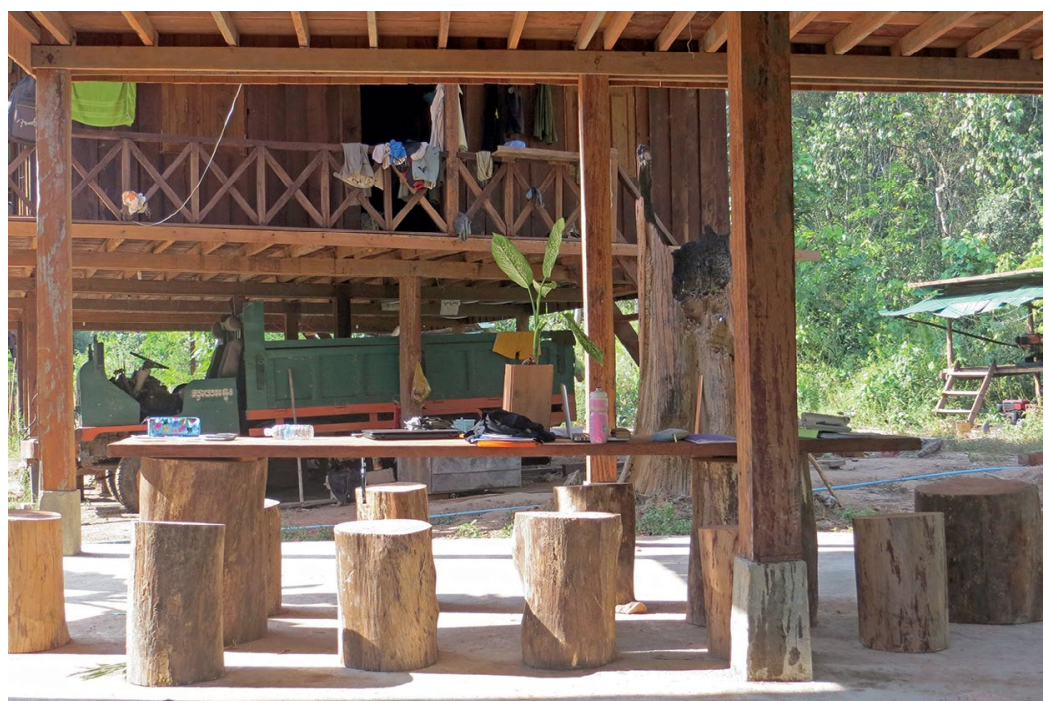

Figure 2: Student study space at Veun Sai-Siem Pang Conservation Area Source: Author. 


\section{Behavioural data collection}

Gibbon observation days were definitely some of my favourite, but they could also be some of the most challenging and frustrating. Days would start before sunrise with a group of half-awake students blindly following the local guide through the park's semidense forest to a designated calling bench located roughly 30 minutes from base camp. Male gibbons (Figure 3) started the morning with a mournful call they hoped would be reciprocated by their female mate (Figure 4) or a potential mate. Juvenile gibbons occasionally joined in with fainter calls. Groups were located by listening to these eerie calls echo across the park from a strategically placed calling bench. Once they started, we would take note of calling times, an estimated caller location, weather conditions and whether a male call would receive a response. When the habituated study group called, we would hurriedly follow our guide until the group was located and begin our behavioural data collection. Observing habituated animals was an experience beyond words. Habituation removes the confines of captivity and allows detailed behavioural data to be collected within the animal's natural habitat. Beyond observing habituated nonhuman primates, the opportunity to be observing a newly discovered species, like the gibbons studied during this field school, added a surreal feeling to the experience.

Being at the mercy of wild animals and factoring this into research was something that was also experienced first-hand. The gibbon calls played a crucial part in locating our habituated group to carry out the day's behavioural data collection; if the group did not call, we could not study them that day. This was resultantly the source of many frustrations. As a gibbon's call is not guaranteed, I soon learnt it was crucial to make smart use of the time we had with the gibbons when we did find them. Maintaining effective group relationships was an easily transferrable skill I also learnt from this experience, as group moral could easily be affected by rising temperatures or the disappointment of a sudden change in plans. This presented a very different group environment to pipetting with a lab partner or chasing up slides for a group presentation.

In addition to tracking through the bush, we also spent a portion of our time writing up field reports and analysing collected samples, such as faecal matter we collected for later hormone analysis. 


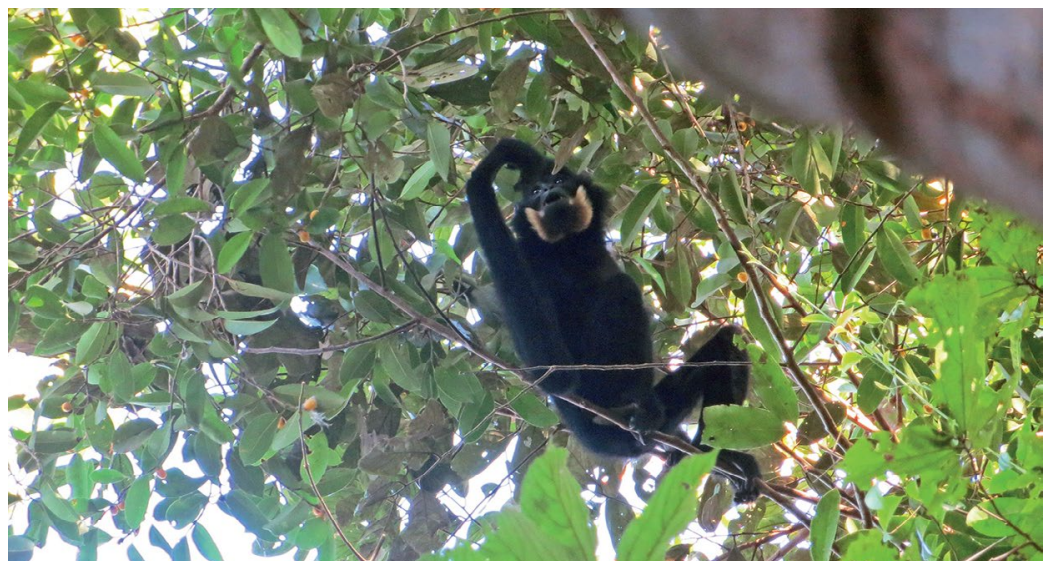

Figure 3: Habituated adult male northern buff-cheeked crested gibbon eats fruit of local gibbon feeding tree

Source: Author.

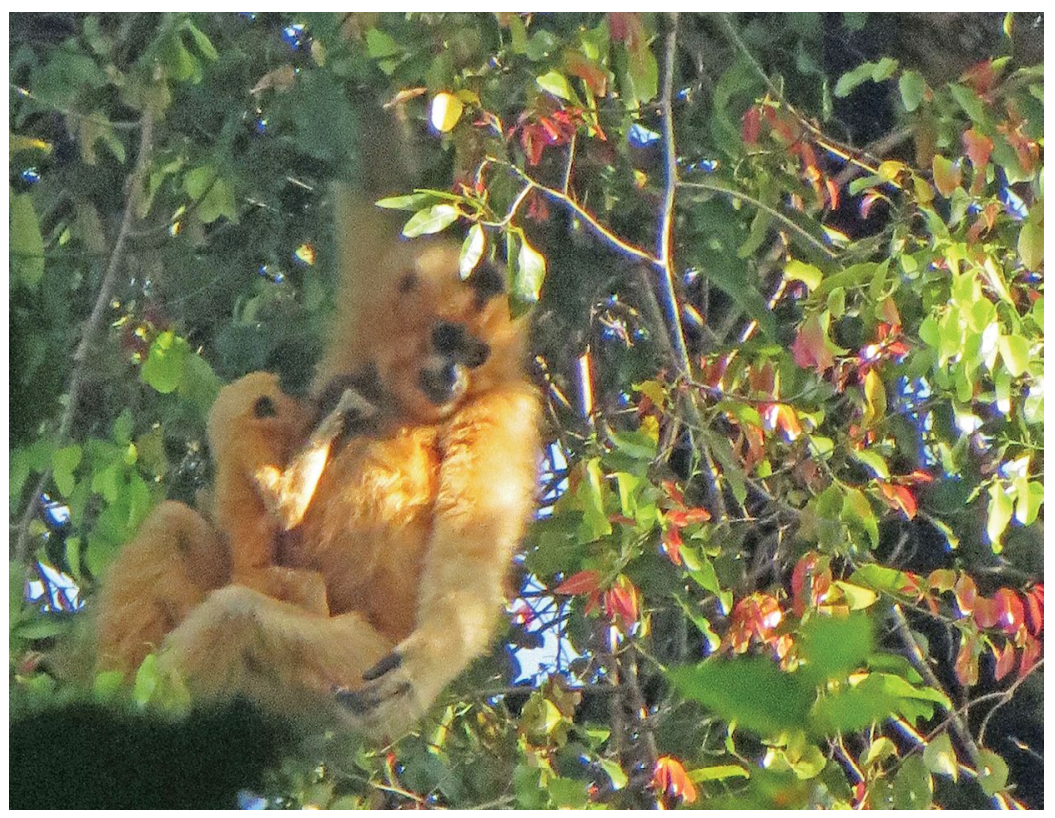

Figure 4: Adult female and infant northern buff-cheeked crested gibbons Source: Author. 


\section{Ecological analysis}

Transact analysis of the evergreen and semi-evergreen, mixed deciduous, riverine and gallery forests that made up the VSSPCA involved not only effectively applying methodologies learnt before entering the field, but also working together with local field guides to correctly identify local tree species. I was able to use some of the skills gained from this exercise-working in a group to collect data despite time constraints, being in an unpredictable environment and navigating cultural or language barriers-not only throughout my Honours year but also when I began my career in data research.

Though our main aim had been to record local vegetation and its use by our study species, we had to consider additional factors such as the impact of local human settlements on available feeding trees. Widespread deforestation was an obvious issue during our stay; we frequently heard logging as we tracked through the forests each day. Additional evidence of human impact on local vegetation included tree tapping for sap, which left gapping burnt-out holes on the sides of older trees. We were confronted by the real-life challenges of doing primate research amidst current threats, and this gave us a more holistic approach and understanding about what it is like to collect data in the fieldgoing far beyond points learnt from a textbook or hour-long lectures. The opportunity to have conversations with locals about how VSSPCA affected their lives further added another valuable component to the research.

\section{Take-home message}

Following three years of a biological science degree that heavily focused on covering scientific theory with an emphasis on laboratory-based practice, completing my studies with an opportunity such as this allowed me to come full circle. Exposure to all forms of learning, I feel, has better equipped me for both further study opportunities and the workforce. I have gained skills in effectively working in unpredictable environments with a diverse group of people, and under unexpected pressures, to produce quality results. I would recommend an experience such as this to all students, regardless of career path, as it presents a once-in-a-lifetime opportunity to learn about the practicalities of field research and to develop problem-solving skills in a way that a classroom does not provide. 


\section{Acknowledgements}

The author thanks Dr Alison Behie for coordinating and providing research guidance during the 2014 Primate Behavioural Ecology Field School. The author would further like to thank the research and ranger teams at VSSPCA for their on-site support.

\section{References}

King A, Behie AM, Hon N, Rawson BM. 2016. Patterns of salt lick use by mammals and birds in northeastern Cambodia. Cambodian J Nat Hist. $1: 40-50$. 
This text is taken from the The Human Voyage: Undergraduate Research in Biological Anthropology: Volume 1, 2017, edited by Alison Behie, published 2017 by ANU eView, The Australian National University, Canberra, Australia.

dx.doi.org/10.22459/HV.01.2017.08 